\title{
Composition of gallstones from hamsters
}

\author{
D. JUNE SUTOR, SUSAN E. WOOLEY, AND ELIZABETH M. GORDON \\ From the Department of Chemistry, University College, London, and the \\ Department of Surgery, Charing Cross Hospital Medical School, London
}

SUMMARY Gallstones from three hamsters were studied. The only crystalline material present in detectable amounts was apatite.

The golden hamster (Cricetus auratus) has become an important experimental model for studies on the effect of diet on the production of gallstones ever since Dam and Christensen (1952) noted their occurrence when studying the relationship of diet to muscular dystrophy. The stones, which weighed between 0.65 and $1.36 \mathrm{mg}$ and varied in colour from nearly white to dark brown-green, were analysed by use of the Liebermann-Burchard reaction to give a cholesterol content of 51 to $94 \%$.

From this it might be assumed that all gallstones found in the hamster as a result of dietary variations should be composed mostly of cholesterol. In a recent study gallstones that were formed in three hamsters did not reveal evidence of cholesterol on chemical analysis and they were analysed by standard $x$-ray diffraction techniques. There were four calculi from one animal, two from another, and one from a third. All the stones were very tiny, approximately $1 \mathrm{~mm}$ in diameter and each weighed about $0.3 \mathrm{mg}$. They were dark in colour, hard, and their shape varied from spherical to flat triangular. Apart from a few pointed nodules the surfaces were smooth.

The $x$-ray powder method can be used for identification when only a small amount of material is available. Four stones were photographed, two from the hamster with four calculi and one from each of the other hamsters. Each stone was mounted with Vaseline on the tip of a glass fibre and photographed using $\mathrm{CuK} \alpha$ radiation and a Unicam goniometer with a camera radius of $3 \mathrm{~cm}$. In every instance the diffraction pattern obtained showed that the only crystalline material present in detectable amounts was apatite (a calcium phosphate). The colour of the stones indicated that bile pigments form part of the calculus but these are either amorphous or present in quantities too small to give an observable $x$-ray pattern.

The chemical constitution of the apatites in the gallstones has not been determined. Hydroxy- and carbonate-apatite are the two most common biological forms. They can be distinguished chemically by their reaction with hydrochloric acid but this is a destructive technique and would use most of the available material.

Apatite is found in human gallstones usually in small amounts but one amorphous stone shown to consist of calcium phosphate by chemical analysis may be predominantly apatite (Sutor and Wooley, 1969; Kirk, 1968). We could not find references to other animal gallstones containing apatite, though Okey (1942) describes the presence of calcium phosphate as well as cholesterol in gallstones formed in guinea pigs.

We thank Professor Dame Kathleen Lonsdale, FRS, for her interest in this work and the Medical Research Council for financial assistance.

\section{REFERENCES}

Dam, H., and Christensen, F. (1952). Alimentary production of gallstones in hamsters. Acta.path. microbiol. scand., 30, 236-242

Kirk, C. J. C. (1968). Private communication.

Okey, R. (1942). Gallstone formation and intake of B vitamins in cholesterol-fed guinea-pig. Proc. Soc. exp. Biol. (N.Y) 51, 349-351.

Sutor, D. J., and Wooley, S. E. (1969). $X$-ray diffraction studies of the composition of gallstones from English and Australian patients. Gut, 10, 681-683. 